\title{
The influence of different acids etch on dental implants titanium surface
}

\author{
Dr. Afya Sahib Diab Al-Radha, ${ }^{1}$.B.D.S; M.Sc; MFDSRCPS (Glasgow),Ph.D (UK). \\ Oral and Maxillofacial Surgery Department; College of Dentistry, \\ Al- Mustansiriyah University, Baghdad, Iraq.
}

\begin{abstract}
:
Purpose: The purpose of the present work was to explore the effect of etching with different acids types, concentration, duration and temperature on titanium dental implant topography.

Materials and Methods: Pure polished titanium discs were subjected to various acids etch.

Disc samples were etched using hydrochloric acid $(\mathrm{HCl})$ sulphuric acid $\left(\mathrm{H}_{2} \mathrm{SO}_{4}\right)$, and nitric acid $\left(\mathrm{HNO}_{3}\right)$ solutions separately for $5 \mathrm{~min}, 15 \mathrm{~min}, 30 \mathrm{~min}, 45 \mathrm{~min}, 60 \mathrm{~min}$. Polished titanium surfaces were used as a control.

Surface roughness was measured using profilometry. Topography was examined using scanning electron microscopy (SEM). Results: The morphology and the surface roughness of titanium discs found to be different after various acids concentration and etching time.

The mean surface roughness values (mean Ra value) of the three acids differ for different acid exposure times. Surface etched with $\mathrm{HNO}_{3}$ had the lowest Ra value for all time intervals. Surfaces etched with $\mathrm{H}_{2} \mathrm{SO}_{4}$ acid had the highest Ra value in the first 5 min. Surface etched with $\mathrm{HCl}$ showed the highest surface roughness following surface exposure for 30, 45 and $60 \mathrm{~min}$.

Conclusions: Roughness resulting from acid etching varied according to acid concentration, type of acid, duration of acid etching procedure, original surface roughness of the substrate and temperature. There are critical time for roughening with acid etching, that after it the acid effect start to smooth titanium surface instead of roughening it.
\end{abstract}

\section{Introduction}

Dental implants have become an important option in treatment plans within dentistry to replace missing teeth. The long term success of an implant is highly dependent upon the ability of the material to integrate with the surrounding bone and connective tissue. ${ }^{1}$ Efforts have been made to develop materials that can accelerate osseointegration. ${ }^{2}$

Many attempts have been made to modify dental implant surfaces in order to improve their biocompatibility, shorten healing times and improve surface characteristics that are involved in implant success. Topography of the biomaterial surface plays an important role in determining cellular response. ${ }^{3}$ The biological response to a dental implant is determined by a number of physical and chemical features of the implant surface, which include mechanical properties and physicochemical properties. ${ }^{4}$ Any interaction between the body tissues and the implant material will be affected by these properties and any changes in one of these groups may affect the other parameters. ${ }^{5,6,7}$

Various surface modifications have been undertaken to improve the surface topography and chemical composition of the implant surface ${ }^{8}$, and these have resulted in higher clinical osseointegration success rates.

Topography of the biomaterial surface plays an important role in determining cellular response. ${ }^{3}$ there is a critical surface roughness that may affect cellular responses according to each cell type. The transmucosal part of the dental implant needs to be smooth, as a rough one will enhance plaque formation. However, at the same time the bony and connective tissue interface requires a porous or a micro-textured surface to promote tissue ingrowth. ${ }^{9}$

Modifying implant surface with acid etching is to make pits to allow bone ingrowth. The surface of the etched implants can be affected by several parameters, such as the original surface roughness, type and concentration of acid, temperature, and time. The etching process is thought to convert the titanium surface by creating a micro-roughness of $0.5-3$ $\mu \mathrm{m}$ with the formation of irregular different depth pits. ${ }^{10}$ It has been suggested that the dissolution of the implant surface can depend on the orientation of the individual titanium grains. ${ }^{11}$

Sul and coworker ${ }^{12}$ showed that the surface morphology of the dual acid etching implant "Osseotite implant" is characterized by needle-like margin structure $\leq 2 \mu \mathrm{m}$ wide and $\leq 1 \mu \mathrm{m}$ depth with a crystallo graphically etched appearance. Klokkevold and coworker ${ }^{13}$ compared the anchorage of etched Osseotite implants and machined surfaces after 1, 2, and 3 months in the rabbit tibia model, and found that the acid etched surface had a higher removal torque than the machined surface after 1 and 2 months of healing respectively.

The benefit of acid etching alone to improve osseointegration was illustrated by Klokkevold and coworker ${ }^{14}$ who showed that the deep pits created during the etching process were filled with bone which contributed to bone interlocking. Many dental implant manufacturers started to use this procedure to prepare titanium surfaces. ${ }^{15}$ However, it has been shown that on some occasions the pits are too small to permit bone ingrowth, and it is thought that this is may be due to either using a weak acid mixture, a low etching temperature, or a short etching time.

In research studies and also in some dental implant companies details of surface modification without precise information on procedure are generally given. For example in case of acid etching the duration and concentration of acid used is often not provided. Therefore it has been felt that it is important to highlight the importance of providing detailed information of acid etched surface modification.

The aim of this study was to explore the effect of etching titanium dental implant surface with different acids types, concentration, duration and temperature on titanium dental implant topography. 


\section{Material and Method}

Discs of $5 \mathrm{~mm}$ in diameter were punched out from annealed titanium sheets $99.6+\%$ (Goodfellow Cambridge Limited, Huntingdon, England). In order to have an accurate evaluation of surface changes a uniform clean surfaces were obtained (mirror polished surface) on one side of each disc by polishing using grinding and a polishing discs (Struers A/S, Ballerup, Denmark) which considered a polished titanium control surface. Discs were then dried in an oven at $40{ }^{\circ} \mathrm{C}$ for $1 \mathrm{hr}$ and left to dry at room temp. The discs were stored in a sealed container.

\section{Etching with heated acids}

Surface modifications with acid were conducted. After each surface modification the discs were ultrasonicated in ethanol for $5 \mathrm{~min}$ and then distilled water for $10 \mathrm{~min}$ at room temperature. The discs were then incubated before being put in the oven at $40{ }^{\circ} \mathrm{C}$ for $1 \mathrm{hr}$ and allowed to dry at room temperature.

The titanium discs were etched with different acid solutions separately for different times, concentrations and temperatures according to requirements for each acid type. An electrical water bath was used to increase and sustain the temperature of the acids.

- Titanium discs were etched with a concentrated hydrochloric acid HCl 37\% (AnalaR, VDR international, Briar, France) at $60{ }^{\circ} \mathrm{C}$ for $5 \mathrm{~min}, 15 \mathrm{~min}, 30 \mathrm{~min}, 45 \mathrm{~min}$ and $60 \mathrm{~min}$.

- $\quad$ Titanium discs were etched with a concentrated sulphuric acid $\mathrm{H}_{2} \mathrm{SO}_{4} 98 \%$ (AnalaR, VDR international, Briar, France) at $80{ }^{\circ} \mathrm{C}$ for $5 \mathrm{~min}, 15 \mathrm{~min}, 30 \mathrm{~min}, 45 \mathrm{~min}, 60 \mathrm{~min}$.

- Titanium discs were etched with concentrated nitric acid $\mathrm{HNO}_{3} 69 \%$ (Sigma-Aldrich, Steinneim, Germany) at $80{ }^{\circ} \mathrm{C}$ for similar time $5 \mathrm{~min}, 15 \mathrm{~min}, 30 \mathrm{~min}, 45 \mathrm{~min}, 60 \mathrm{~min}$.

\section{Scanning electron microscopy (SEM examination)}

Topographic inspection was conducted using a scanning electron microscope (SEM Tech Ltd, Bonsall, Derbyshire, U.K.). All samples were attached by adhesive to aluminum SEM stubs and examined at $20 \mathrm{kV}$ in the secondary emission mode in a PC-controlled ISI 60 scanning electron microscope.

Measurement of surface roughness

Non-contact optical Proscan profilometry was used to measure the surface roughness (Proscan 2000, Scantron Industrial Products Ltd. Monarch centre, Taunton, England). The measurements were conducted in an X and Y direction, and the scanned area was $2 \times 2 \mathrm{~mm}$. The measurement was taken for 20 lines in the Y axis; 250 spots in each line were measured twice. The final analysis was conducted in an area of $1.2 \mathrm{~mm} \times 1.2 \mathrm{~mm}$ in order to avoid edge effects.

Ra measurement was calculated for each sample: Ra: "is the arithmetic mean of the absolute values of the surface point departures from the mean plane within the sampling area" ${ }^{16}$ (Macdonald et al., 2004).

Statistics

Statistical analysis was carried out using Excel and SPSS (Statistical Package for Social Sciences)

The statistical methods used to analyze and assess the results were, descriptive statistic: mean, standard error; International statistic: T-test, ANOVA test.

After verification of the normal distribution and the homogeneity of the variance, an analysis of the variance (ANOVA) was used to asses any significant differences among selected group. For multiple comparisons test (Post Hoc multiple comparisons) LSD (least significant difference) was used to determine the specific differences between the means of the group members. The probability value ( $\mathrm{p}$-value) was considered significant at $\mathrm{P}<0.05$ and highly significant if $\mathrm{P}<$ 0.01 .

\section{Results}

A uniform mirror polished surface were obtained on one side of each disc, for polished titanium surface with base line roughness $0.056 \mu \mathrm{m}$ and considered as a polished titanium control surface.

Surface reactions to different acids were inspected and analysed by scanning electron microscopy and by profilometry.

\section{Etching with heated acids}

An immediate reaction with $\mathrm{HCl}$ acid was observed after a few seconds through the production of bubbles on the titanium surface. The colour of these surfaces changed according to etching duration ranging from a slight decrease in brightness and slight dull colour, for 5 and 15 min etching duration respectively, to appearance of a coarse surface visible to the naked eye following 30, 45 and $60 \mathrm{~min} \mathrm{HCl}$ acid exposure. Less powerful reactions were seen with $\mathrm{H}_{2} \mathrm{SO}_{4}$ with changing in colour from a bright mirror image to a dull grey colour for all time intervals. For $\mathrm{HNO}_{3}$ no visible alterations were seen and disc surfaces still have a bright mirrored surface.

The mean surface roughness values (mean Ra value) of the three acids for different acid exposure times can be seen in Fig 1. Surface etched with $\mathrm{HNO}_{3}$ had the lowest Ra value for all time intervals. This matches lack of change observed visually, and there were no significant differences between the time intervals.

Surfaces etched with $\mathrm{H}_{2} \mathrm{SO}_{4}$ acid had the highest $\mathrm{Ra}$ value in the first 5 min with a highly significant difference between $\mathrm{HNO}_{3}$ acid etched surface $(\mathrm{P}<0.01)$ and significant difference with $\mathrm{HCl}$ acid etched surface $(\mathrm{P}<0.05)$. In 15 min etching time, both $\mathrm{H}_{2} \mathrm{SO}_{4}$ and $\mathrm{HCl}$ acid etched surfaces showed dramatic increases in Ra value with highly significant difference with $\mathrm{HNO}_{3}$ acid etched surface but not between themselves.

Surface etched with $\mathrm{HCl}$ showed the highest surface roughness following surface exposure for 30, 45 and $60 \mathrm{~min}$. However, highly significant differences were found in Ra values between etching time in $\mathrm{HCl}$ acid etched group and $\mathrm{H}_{2} \mathrm{SO}_{4}$ given in $\mathrm{P}<0.001$. Also, highly significant differences appeared between all types of acids with each time group.

Surprisingly, all acids showed an increase in Ra value at 30 min etching time followed by decrease at 45 min etching time, then return to increase in 60 min etching time.

DOI: 10.9790/0853-1508098791 $\quad$ www.iosrjournals.org $\quad 88 \mid$ Page


Etching with $\mathrm{HCl}$ resulted in a relatively continuous series of SEM images (Fig 2), in which a fine trabecular and round porous structure was observed. The surface roughness appeared to increase with etching time as shown by surface topography analysis. The shape of surface pores appeared small and mesh-like and with greater etching times there were areas containing collections of larger pores, which can be seen after $45 \mathrm{~min}$ acid exposure. After $60 \mathrm{~min}$ the surface showed slight changes, such as the formation of lines in a rectangular pattern instead of the round pores previously observed. At low SEM magnification a mesh of elevations was seen.

Different images were seen with $\mathrm{H}_{2} \mathrm{SO}_{4}$ (Fig 3) in which the roughness started to appear after 15 min etching as widely separated small holes. There was a small increase in the number of these holes after 30 min etching, with a dramatic increase in their size (diameter) and appearance of shallow hills/peaks (waviness) on the surface. After $\mathrm{H}_{2} \mathrm{SO}_{4}$ exposure for $60 \mathrm{~min}$, (and particularly $45 \mathrm{~min}$ ), localised collections of holes with connections between them were observed. No surface changes were observed for $\mathrm{HNO}_{3}$ exposure (fig 4.).

\section{Discussion}

This work shows that a slight difference in temperature or concentration, or duration, and many other parameter have heavy impacts on titanium surface topography

For surface modification by acid etching, the etching was started stepwise. At first, with different dilutions 20, 40, $60,80,100 \%$ concentration of each acid at room temperature for durations up to $1 \mathrm{~h}$. No effects could be observed.

The next step was to elevate the temperature. It was decided to start with $60{ }^{\circ} \mathrm{C}$ (according to ASTM, F 86-04). An immediate effect was observed in the case of $\mathrm{HCl}$ identified by bubble formation during the etching procedure and change in disc colour. No effects were observed for $\mathrm{HNO} 3$ or $\mathrm{H}_{2} \mathrm{SO}_{4}$ acid etching. Therefore the etching temperature was increased for both of these acids to $80{ }^{\circ} \mathrm{C}$. An effect then started to be observed in $\mathrm{H}_{2} \mathrm{SO}_{4}$ acid etching, but not in case of $\mathrm{HNO}_{3}$ acid etching.

The results showed that a range of treatments of titanium produced different surface topographies, as first indicated by Xavier and coworker ${ }^{8}$.

In order to generate accurate base-line data and have accurate comparisons of the modified surfaces, standard polished surfaces were produced to use as control. These polished surfaces appear extremely smooth to the naked eye with a shiny mirror surface, and Ra value $=0.047 \mu \mathrm{m}$. This is close to the Ra values found by Nagassa and coworker ${ }^{17}$ of $0.053 \mu \mathrm{m}$ for their polished titanium surfaces.

\section{Acid etching}

Acid etching is one of the major surface modifications that has been used in previous studies and they are also found commercially on a number of implant types (e.g. Osseotite, $3 i$ implant Innovations, West Palm Beach, USA). The clinical performance of these implants are shortened healing times when compared to machined surface implants has been widely documented ${ }^{18}$.

In this study $\mathrm{HCl}$ appeared to be the most effective acid etchant on the titanium surface increasing the surface area by creating many acid etched pits and grooves that had a specific character. ${ }^{19}$ The SEM images appeared similar to those seen in work published by Szumukler-Moncler and coworker, ${ }^{15}$ when they examined the commercially available SLA-ITI implant specifically in the region of the implant surface where the surface was only etched with no blasting (the area between the threads).

There are similarities also between the images seen in this study for acid etching with $\mathrm{H}_{2} \mathrm{SO}_{4}$ and the pictures obtained by Lewandowska and coworker ${ }^{20}$ when they etched titanium surfaces with a mixture of $\mathrm{H}_{2} \mathrm{SO}_{4}$ and $\mathrm{H}_{2} \mathrm{O}_{2}$.

The highest roughness seen from acid etching alone was produced with $\mathrm{HCl}$ for 30 minutes duration $(0.588 \mu \mathrm{m})$. This value is still lower than that reported by Szumukler-Moncler et al., ${ }^{18}$ for Osseotite implant surface manufactured by $3 \mathrm{i}$ implant (Implant Innovations, West Palm Beach, USA) with an Ra value of $0.96 \pm 0.12 \mu \mathrm{m}$. These later implants are subjected to high concentrations of HF acid (15 wt \%) before etching in order to remove the oxide layer, followed by a further etching procedure. This action may exaggerate the etching process in a manner similar to etching after blasting, where the blasting process increases the surface area of the titanium, enhancing the action of the acid etchant and leading to higher Ra values (as found in this Results chapter). The 3i implants may also have had a rougher pre-etched surface, if they have a machined surface. Guizzardi et al., ${ }^{21}$ reported an Ra for their machined surfaces of $0.56 \mu \mathrm{m}$ which is rougher than the polished surfaces used in this study. This may affect the outcome of acid etching leading to a higher final surface roughness.

Etching with $\mathrm{HNO}_{3}$ appeared to show no visible changes on the titanium surface. There were no significant differences seen between the Ra values of $\mathrm{HNO}_{3}$ etched surfaces and polished surfaces $(\mathrm{P}=0.098)$. In addition, SEM images were unable to show any changes. These findings coincide with those of Xavier et al., ${ }^{8}$ as they also failed to find any effect of etching with $\mathrm{HNO}_{3}$ on surface roughness.

It was interesting to discover that surface roughness decreased after a specific duration of etching time. In this study the threshold etching time was $30 \mathrm{~min}$, after which the Ra values started to decrease. This has recently been reported by Coelho et al., ${ }^{22}$, and the importance of controlling any acid etching procedure was emphazised, as over-etching resulted in decreased surface topography and reduced mechanical properties.

\section{Conclusions}

Titanium is an amenable material for designing of implant and it is possible to modify the surface using a variety of protocols.

Roughness resulting from acid etching varied according to acid concentration, type of acid, duration of acid etching procedure, original surface roughness of the substrate and temperature. 
There are critical time for roughening with acid etching, that after it the acid effect start to smooth titanium surface instead of roughening it.

\section{References}

[1]. Größner-Schreiber B, Griepentrog M, Haustein I, Müller W, Lange K, Briedigkeit H, Go bel U. (2001) Plaque formation on surface modified dental implants: An in vitro study. Clin Oral Impl Res. 12:543-551.

[2]. Pier-Francesco A, Adams R, Waters M, Williams D. (2006) Titanium surface modification and its effect on the adherence of Porphyromonas gingivalis: an in vitro Study. Clin Oral Impl Res. 17:633-637.

[3]. He J, Zhou W, Zhou X, Zhong X, Zhang X, Wan P, Zhu B, Chen W. (2008) The anatase phase of nanotopography titania plays an important role on osteoblast cell morphology and proliferation. J Mater Sci: Mater Med. 19:3465-3472.

[4]. Mabbouxa F, Ponsonnetb L, Morriera J, Jaffrezicb N, Barsottia O. (2004) Surface free energy and bacterial retention to saliva-coated dental implant materials - an in vitro study. Colloids Surf B: Biointerfaces. 39:199-205.

[5]. Worthington P, Lang B, Rubenstein J. (2003) osseointegration in dentistry: An introduction. $2^{\text {nd }}$ ed. Chicago: Quintessence.

[6]. Albrektsson T, Wennerberg A. (2004) Oral implant surfaces: part 1 - review focusing on topographic and chemical properties of different surfaces and in vivo responses to them. Int J Prosthod. 17:536-43.

[7]. Le Gue hennec L, Soueidan A, Layrolle P, Amouriq Y. (2007) Surface treatments of titanium dental implants for rapid osseointegration. Dent Mater. 23:844-54.

[8]. Xavier S, Carvalho P, Beloti M, Rosa A. (2003) Response of rat bone marrow cells to commercially pure titanium submitted to different surface treatments. Journal of Dentistry. 31:173-180.

[9]. Größner-Schreiber B, Herzog M, Hedderich J, Dück A, Hannig M, Griepentrog M. (2006) Focal adhesion contact formation by fibroblasts cultured on surface-modified dental implants: an in vitro study. Clin Oral Impl Res. 17:736-745.

[10]. Steinemann S. (1998) Titanium-the material of choice?. Periodontol 2000. 17:7-21.

[11]. Massaro C, Rotolo P, De Riccardis F, Milella E. (2002) comparative investigation of the surface properties of commercial titanium dental implants. Part 1: chemical composition. J Mater Sci Mater Med. 13:535-548.

[12]. Sul Y, Byon E, Wennerberg A. (2008) Surface characteristic of electrochemically oxidized implant and acid-etched implant: surface chemistry, morphology, pore configurations, oxide thickness, crystal structure, and roughness. Int J Oral Maxollofac Implants. 23:631-640.

[13]. Klokkevold P, Johnson P, Dadgostari S, Caputo A, Davies J, Nishimura R. (2001) Early endosseous integration enhanced by dual acid etching of titanium: A removal torque study in the rabbit. Clin Oral Implant Res. 12:350 -357.

[14]. Klokkevold P, Nishimura R, Adachi M. (1997) Osseointegration enhanced by chemical etching of the titanium surface. Clin Oral Implants Res. 8:442447.

[15]. Szmukler-Moncler S, Perrin D, Ahossi V, Magnin G, Bernard J. (2004) Biological properties of acid etched titanium implants: effect of sandblasting on bone anchorage. Appl Biomater. 68B:149-159.

[16]. Macdonald W, Campbell P, Fisher J, Wennerberg A (2004) Variation in surface texture measurements. J Biomed Mater Res Part B: Appl Biomater. 70B: $262-269$.

[17]. Nagassa M, Daw A, Rowe W, Carley A, Thomas D, Moseley R. (2008) Optimization of the hydrogen peroxide pre-treatment of titanium: surface characterisation and protein adsorption. Clin Oral Implants Res. 19:1317-1326.

[18]. Szmukler-Moncler S, Testori T, Bernard J. (2004) Etched implants: A comparative surface of four implant systems. J Biomed Mater Res Part B: Appl Biomater. 69B:46-57.

[19]. Wen H, Liu Q, De Wlin J, De Groot K. (1998) Preparation of bioactive microporous titanium surface by a new two-step chemical treatment. J Mater Sci Mater Med. 9:121-128.

[20]. Lewandowska M, Włodkowska M, Olkowski R, Roguska A, Polak B, Pisarek M, Lewandowska-Szumieł M, Kurzydłowsk K. (2007) Chemical surface modifications of titanium implants. Macromol Symp. 253:115-121.

[21]. Guizzardi S, Galli C, Martini D, Belletti S, Tiniti A, Raspanti M, Taddei P, Ruggeri A, Scandroglio R. (2004) Different titanium surface treatment influence human mandibular osteoblast response. J Periodontol. 75:273-182.

[22]. Coelho P, Granjeiro J, Romanos G, Suzuki M, Silva N, Cardaropoli G, Thompson V, Lemons J. (2009) Basic research methods and current trends of dental implant surfaces. Biomed Mater Res Part B: Appl Biomater. 88B:579-596.

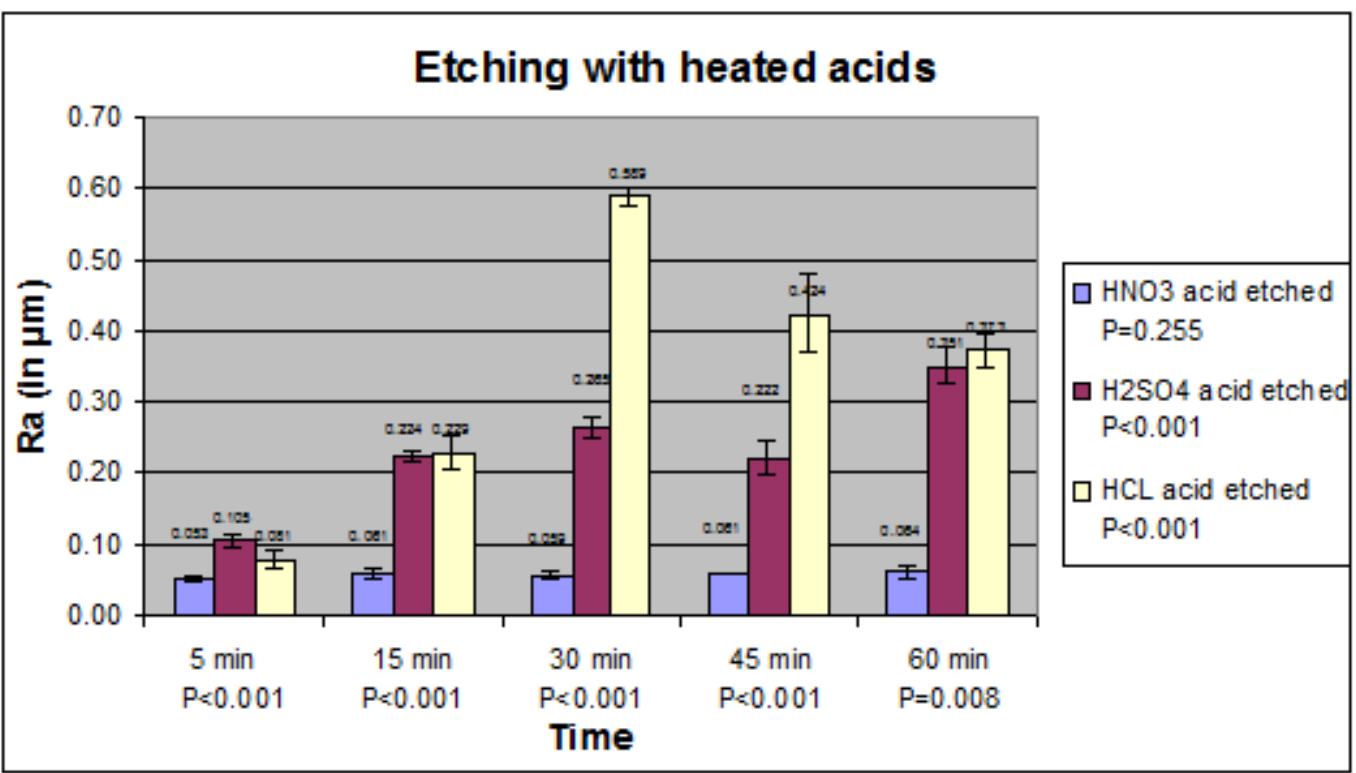

Figure 1 Average Ra values (in $\mu \mathrm{m}$ ) and standard error of titanium surfaces etched with different heated acids as quantified by profilometry. 
The Influence Of Different Acids Etch On Dental Implants Titanium Surface
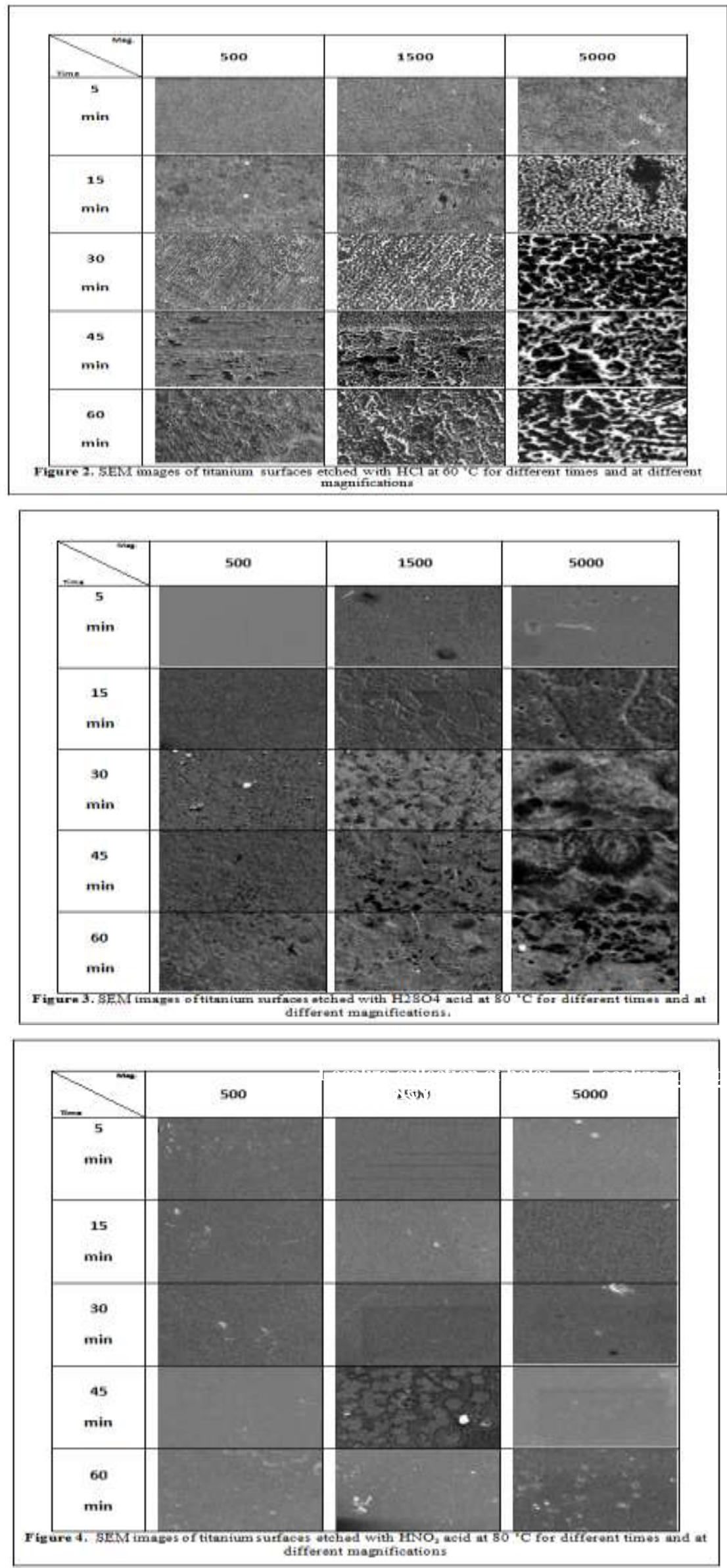